\title{
Crystallographic Determination of the Positions of the Copper Cations in Zeolite
} MFI.

\author{
Bernard F. MENTZEN \\ RZHGC, 5 rue Marcel Desplaces, F-69330 Meyzieu, France
}

\section{Gérard BERGERET}

IRCELYON (Institut de Recherches sur la Catalyse et l'Environnement de Lyon), UMR 5256 CNRS-Université, 2 avenue Albert-Einstein, F-69626 Villeurbanne, France 


\section{TABLE 1S. $\quad \mathrm{H}_{1.04} \mathrm{Cu}(\mathrm{I})_{1.19} \mathrm{Cu}(\mathrm{II})_{0.51} \mathrm{MFI} 25^{\circ} \mathrm{C} \quad-\quad$ Phase $\mathrm{Cu}(1.7)$}

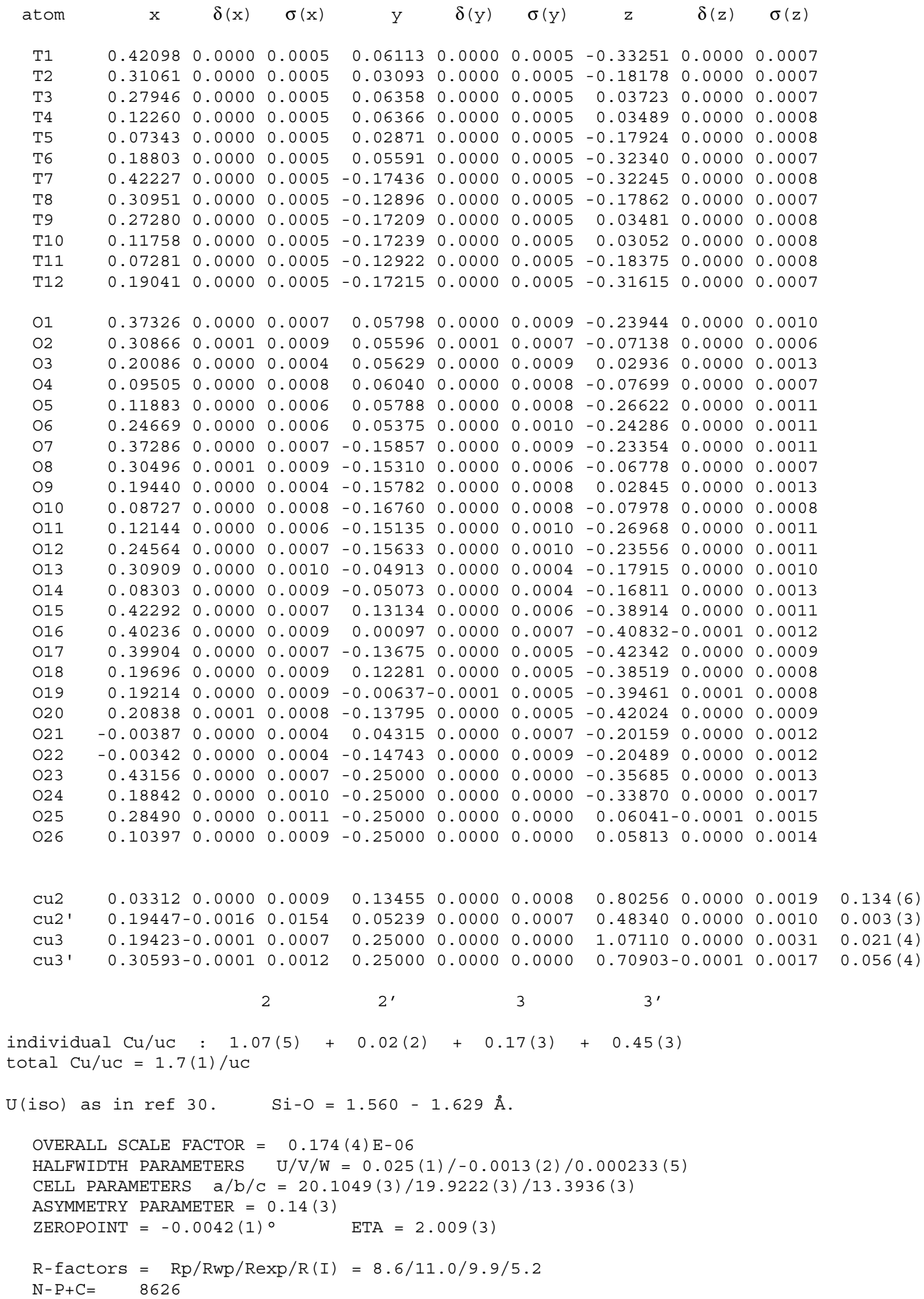


TABLE 2S. $\quad \mathrm{H}_{1.99} \mathrm{Cu}(\mathrm{I})_{2.37} \mathrm{Cu}(\mathrm{II})_{0.00} \mathrm{MFI} 25^{\circ} \mathrm{C} \quad-\quad$ Phase $\mathrm{Cu}(2.4)$

\begin{tabular}{|c|c|c|c|c|c|c|c|c|c|c|}
\hline atom & $\mathrm{x}$ & $\delta(x)$ & $\sigma(\mathrm{x})$ & $\mathrm{y}$ & $\delta(y)$ & $\sigma(y)$ & $\mathrm{z}$ & $\delta(z)$ & $\sigma(z)$ & \\
\hline T1 & 0.42075 & 0.0000 & 0.0005 & 0.06106 & 0.0000 & 0.0006 & -0.33221 & 0.0000 & 0.0007 & \\
\hline T2 & 0.30862 & 0.0000 & 0.0006 & 0.02911 & 0.0000 & 0.0005 & -0.18518 & 0.0000 & 0.0007 & \\
\hline T3 & 0.27936 & 0.0000 & 0.0005 & 0.06476 & 0.0000 & 0.0006 & 0.03463 & 0.0000 & 0.0007 & \\
\hline $\mathrm{T} 4$ & 0.12237 & 0.0000 & 0.0005 & 0.06191 & 0.0000 & 0.0006 & 0.03196 & 0.0000 & 0.0008 & \\
\hline T5 & 0.06999 & 0.0000 & 0.0005 & 0.02999 & 0.0000 & 0.0005 & -0.18051 & 0.0000 & 0.0008 & \\
\hline $\mathrm{T} 6$ & 0.18582 & 0.0000 & 0.0005 & 0.05652 & 0.0000 & 0.0006 & -0.32376 & 0.0000 & 0.0007 & \\
\hline $\mathrm{T} 7$ & 0.42291 & 0.0000 & 0.0005 & -0.17301 & 0.0000 & 0.0005 & -0.32480 & 0.0000 & 0.0008 & \\
\hline T8 & 0.30980 & 0.0000 & 0.0006 & -0.12946 & 0.0000 & 0.0005 & -0.17864 & 0.0000 & 0.0007 & \\
\hline T9 & 0.27496 & 0.0000 & 0.0005 & -0.17412 & 0.0000 & 0.0005 & 0.03607 & 0.0000 & 0.0008 & \\
\hline T10 & 0.12052 & 0.0000 & 0.0005 & -0.17352 & 0.0000 & 0.0005 & 0.03228 & 0.0000 & 0.0008 & \\
\hline T11 & 0.07236 & 0.0000 & 0.0005 & -0.12844 & 0.0000 & 0.0005 & -0.18113 & 0.0000 & 0.0008 & \\
\hline T12 & 0.19004 & 0.0000 & 0.0006 & -0.17322 & 0.0000 & 0.0005 & -0.31442 & 0.0000 & 0.0007 & \\
\hline $\mathrm{O} 1$ & 0.37139 & 0.0000 & 0.0007 & 0.06091 & 0.0000 & 0.0010 & -0.24108 & 0.0000 & 0.0011 & \\
\hline $\mathrm{O} 2$ & 0.30862 & 0.0000 & 0.0010 & 0.05633 & 0.0000 & 0.0008 & -0.07335 & 0.0000 & 0.0007 & \\
\hline $\mathrm{O} 3$ & 0.20074 & 0.0000 & 0.0005 & 0.05858 & 0.0000 & 0.0010 & 0.02574 & 0.0000 & 0.0012 & \\
\hline 04 & 0.09312 & 0.0000 & 0.0009 & 0.06296 & 0.0000 & 0.0009 & -0.07838 & 0.0000 & 0.0008 & \\
\hline 05 & 0.11583 & 0.0000 & 0.0007 & 0.05989 & 0.0000 & 0.0009 & -0.26728 & 0.0000 & 0.0011 & \\
\hline 06 & 0.24529 & 0.0000 & 0.0007 & 0.05233 & 0.0000 & 0.0011 & -0.24602 & 0.0000 & 0.0011 & \\
\hline 07 & 0.37337 & 0.0000 & 0.0008 & -0.15873 & 0.0000 & 0.0010 & -0.23592 & 0.0000 & 0.0012 & \\
\hline 08 & 0.30840 & 0.0000 & 0.0010 & -0.15729 & 0.0000 & 0.0007 & -0.06920 & 0.0000 & 0.0008 & \\
\hline 09 & 0.19683 & 0.0000 & 0.0005 & -0.15851 & 0.0000 & 0.0008 & 0.02812 & 0.0000 & 0.0013 & \\
\hline 010 & 0.08899 & 0.0000 & 0.0009 & -0.16583 & 0.0000 & 0.0008 & -0.07713 & 0.0000 & 0.0009 & \\
\hline 011 & 0.12177 & 0.0000 & 0.0007 & -0.15345 & 0.0000 & 0.0010 & -0.26436 & 0.0000 & 0.0012 & \\
\hline 012 & 0.24493 & 0.0000 & 0.0007 & -0.15496 & 0.0000 & 0.0010 & -0.23277 & 0.0000 & 0.0013 & \\
\hline 013 & 0.31164 & 0.0000 & 0.0010 & -0.04998 & 0.0000 & 0.0005 & -0.18607 & 0.0000 & 0.0010 & \\
\hline 014 & 0.08154 & 0.0000 & 0.0009 & -0.04957 & 0.0000 & 0.0005 & -0.17075 & 0.0000 & 0.0014 & \\
\hline 015 & 0.41826 & 0.0000 & 0.0008 & 0.13240 & 0.0000 & 0.0007 & -0.38634 & 0.0000 & 0.0012 & \\
\hline 016 & 0.40360 & 0.0000 & 0.0010 & 0.00038 & 0.0000 & 0.0007 & -0.40757 & 0.0000 & 0.0013 & \\
\hline 017 & 0.40103 & 0.0000 & 0.0008 & -0.13494 & 0.0000 & 0.0006 & -0.42500 & 0.0000 & 0.0011 & \\
\hline 018 & 0.19464 & 0.0000 & 0.0010 & 0.12535 & 0.0000 & 0.0006 & -0.38216 & 0.0000 & 0.0010 & \\
\hline 019 & 0.19188 & 0.0000 & 0.0011 & -0.00495 & 0.0000 & 0.0006 & -0.39827 & 0.0000 & 0.0010 & \\
\hline $\mathrm{O} 20$ & 0.20714 & 0.0000 & 0.0010 & -0.13607 & 0.0000 & 0.0006 & -0.41693 & 0.0000 & 0.0010 & \\
\hline 021 & -0.00552 & 0.0000 & 0.0005 & 0.04579 & 0.0000 & 0.0008 & -0.20395 & 0.0000 & 0.0013 & \\
\hline 022 & -0.00281 & 0.0000 & 0.0005 & -0.14623 & 0.0000 & 0.0009 & -0.20386 & 0.0000 & 0.0013 & \\
\hline 023 & 0.43120 & 0.0000 & 0.0009 & -0.25000 & 0.0000 & 0.0000 & -0.35900 & 0.0000 & 0.0015 & \\
\hline $\mathrm{O} 24$ & $0.19252-$ & -0.0001 & 0.0012 & -0.25000 & 0.0000 & 0.0000 & -0.33763 & 0.0000 & 0.0017 & \\
\hline 025 & 0.28755 & 0.0000 & 0.0012 & -0.25000 & 0.0000 & 0.0000 & 0.06615 & 0.0000 & 0.0016 & \\
\hline 026 & $0.10488-$ & -0.0001 & 0.0010 & -0.25000 & 0.0000 & 0.0000 & 0.06319 & -0.0001 & 0.0015 & \\
\hline cul & -0.01897 & 0.0000 & 0.0011 & 0.25000 & 0.0000 & 0.0000 & 1.03775 & 0.0000 & 0.0021 & \\
\hline cu2 & 0.02997 & 0.0001 & 0.0010 & 0.13878 & 0.0000 & 0.0010 & 0.80013 & 0.0002 & 0.0022 & \\
\hline cu2' & 0.19412 & 0.0000 & 0.0066 & 0.05487 & 0.0000 & 0.0008 & 0.47995 & 0.0000 & 0.0012 & $0.055(4)$ \\
\hline cu3 & 0.19310 & 0.0001 & 0.0010 & 0.25000 & 0.0000 & 0.0000 & 1.06715 & 0.0002 & 0.0038 & $0.025(3)$ \\
\hline cul' & 0.30406 & 0.0001 & 0.0016 & 0.25000 & 0.0000 & 0.0000 & 0.71815 & -0.0002 & 0.0020 & $0.062(3)$ \\
\hline
\end{tabular}

$$
\begin{array}{lllll}
1 & 2 & 2^{\prime} & 3
\end{array}
$$

individual $\mathrm{Cu} / \mathrm{uc}: 0.18(3)+1.12(4)+0.44(4)+0.20(4)+0.50(4)$

total $\mathrm{Cu} / \mathrm{uc}=2.4(2)$

$\mathrm{U}($ iso) as in ref $30 . \quad \mathrm{Si}-\mathrm{O}=1.563-1.633 \AA$.

OVERALL SCALE FACTOR $=0.394(1) \mathrm{E}-06$

HALFWIDTH PARAMETERS U/V/W $=0.024(1) /-0.0025(1) / 0.000247$ (5)

CELL PARAMETERS $\mathrm{a} / \mathrm{b} / \mathrm{c}=20.1084(2) / 19.936(2) 2 / 13.4072(1)$

ASYMMETRY PARAMETER $=1.7(1)$

ZEROPOINT $=-0.0028(0)^{\circ} \quad$ ETA $=0.579(7)$

$\operatorname{Rp} / \operatorname{Rwp} / \operatorname{Rexp} / \mathrm{R}(\mathrm{I})=7.3 / 8.4 / 5.8 / 6.2$

$\mathrm{N}-\mathrm{P}+\mathrm{C}=\quad 7522$ 